\title{
Perspectives of Students Labeled Intellectually Disabled at College: Using Disability Studies in Education as a Lens to Contemplate Inclusive Postsecondary Education
}

\author{
Jessica Bacon \\ Department of Teaching and Learning, Montclair State University, \\ Montclair, NJ, USA \\ baconj@montclair.edu \\ Susan Baglieri \\ Department of Teaching and Learning, Montclair State University, \\ Montclair, NJ, USA \\ Baglieris@montclair.edu
}

\begin{abstract}
This study reports on the experiences of students with intellectual disability labels who participated in inclusive postsecondary education (IPSE) at a public university. A disability studies framework is employed to discern and critique the aims of IPSE programs and forefront the perspectives of persons who are identified as intellectually disabled. Qualitative participant-observation data was gathered and analyzed to describe how participants narrate ways they understand and value reciprocal relationships and working towards in(ter)dependence as productive and key aspects of their experience at a college. Implications of attending to student voice to guide our program development is discussed along with broader implications for the field.
\end{abstract}

\section{Keywords}

inclusive postsecondary education - student voice - disability studies - intellectual and developmental disability 
Inclusive postsecondary education (IPSE) programs that recruit students identified as intellectually and developmentally disabled (IDD) have been operating for several decades and are quite varied across the world (Grigal et al., 2012; McEathron et al., 2013; Neubert et. al, 2001). Marked growth and attention to these programs can be attributed to both the ongoing commitment to providing access and opportunity in higher education to people labeled with IDD, and in the United States (US) to increased visibility and support in federal policy. In this paper, we report on an IPSE program, referred to here, as the Inclusive College Project (ICP), which was started by the co-authors at a university in the Northeastern US.

For the past five years, the ICP has hosted groups of participants who are registered in (a) a regional day program that serves clients ages 21 and older and (b) students ages 18-21 enrolled in a local school district's transition program. The ICP's development is characterized by its efforts to increase access for the broader community of traditionally "college-age" adults with IDD to what the campus has to offer. These efforts have enabled participants labeled with IDD access to environments that have historically been closed to them and have provided opportunities for traditionally enrolled college students to learn alongside individuals from whom they have traditionally been segregated from during K-12 education. This is particularly meaningful in the state where the ICP is located, considering only $8.3 \%$ of students with IDD labels are educated in general education for $80 \%$ or more of their school day (USDOE, 2017).

Throughout the founding and development of the ICP, we have engaged in an ongoing exploratory study using qualitative methodologies. The purpose of this paper is to highlight participant perspectives on their experiences of college, which according to Vroman (2019), are underrepresented in the literature. A conceptual framework informed by disability studies in education (DSE) frames the questions: 1) What do participants describe as meaningful about being a part of the ICP?; and 2) How are IPSE participant perspectives driving ongoing research and program development in the field?

Disability studies in Education (DSE) is an eclectic, interdisciplinary field of study rooted in the broader field of Disability Studies (Danforth and Gabel, 2006; Kristiansen et al., 2008). DSE strives to emphasize the impact that 
ableism/disableism has on the educational experiences of those who are deemed or identify as being disabled (Campbell, 2009; Linton, 1998; Oliver and Barnes, 2012; Nussbaum, 2006). Researchers using this lens strive to be critical of assumptions that acquiesce to or enforce compulsory able-bodiedness and able-mindedness (Kafer, 2013; McRuer, 2006). Dominant themes in education and disability research, for example, often relate to how well people with disabilities are approximating ways of learning, behaving, interacting, communicating, and achieving attributed to non-disabled people. Instruction may emphasize teaching skills assumed important for disabled people to acquire because it is assumed that non-disabled people have mastered them. A climate of compulsory able-mindedness has created educational contexts in which access to full participation is predicated on assimilating into normative learning and behavior (Slee, 2007), which Mitchell, et al. (2014) describe as practices of "inclusionism." When young people do not seem to master particular skills or competencies presumed necessary for participation in "general" education, they are often prevented from accessing these environments. In K-12 schools, students labeled with IDD are among those most frequently segregated into self-contained environments (USDOE, 2017).

DSE is primarily interpreted as advocating for expansion of opportunity and participation through inclusive education in schools. The particular view of inclusive education in DSE avoids the assumption that the main way to study or improve inclusivity in schools and communities' rests on the ability of people with disabilities to act and approximate the assumed competencies of non-disabled people. Instead, DSE researchers focus on how educational institutions can create access, systems, and practices that support and enable people with disabilities to live and learn in their schools and communities without such participation being predicated on "overcoming" characteristics associated with disability. In the context of higher education for instance, rather than asking how well a person with a disability can fit into the college environment as it currently is, a DSE lens re-frames the question to ask how an environment can be re/created to encompass disability.

To date, the literature base on IPSE programs has not largely engaged DSE as a conceptual framework to support the development of programs or the associated growing body of scholarship. O'Brien and Bonati (2019), for example, note such gaps and advocate for the use of disability studies as a framework for IPSE programs to introduce and sustain fully inclusive programming. Vroman (2019) cites Hart's (2013) vision for IPSE programming stating that "It's not about bringing special education to higher education. It's about providing the supports and accommodations that will assist the student in being successful and participating in that class, and learning" (Rethinking College, 2013, cited in 
Vroman, 2019). However, O'Brien (2019: 271) evaluated and critiqued attempts in the US to standardized IPSE programs through set outcomes and states: "The vocabulary and grammar of this disability focused initiative shows its origin in the world of special education and disability services." Upon our further interrogation of the literature base, we also question whether the foundational and conceptual knowledge-base of special education still permeates a great deal of IPSE research and programming. At the same time, DSE scholars have paid scant attention to IPSE programs within their development as a field. This article is an attempt to coalesce these fields of study that have many aligned goals, such as increased inclusion of disabled people in schools and society. Ultimately the merging of these knowledge bases may enrich one another.

Program Goals and Student Voice in IPSE Literature

Past reviews of literature on IPSE have pointed out that a barrier to systematic understanding of related research and practice is that there has not been a clear taxonomy or common terminology used to describe the varied group that comprise postsecondary programs that recruit students labeled with IDD (Neubert et al., 2001; Thoma et al., 2011). Based on a review of 24 peer-reviewed articles published between 2001-2010, Thoma et al. (2011) noted that there is lack of cohesion in the nature, goals, and objectives of programs and that data-driven reports of research are limited by both number of studies and numbers of participants. McEathron et al. (2013), Papay and Bambara (2011), and Grigal et al. (2012) have each aimed to research, classify, and define common characteristics of programs to better define IPSE. One reason attempts have been made to create a taxonomy and standards guiding program development is because many programs have been operating as highly or moderately segregated programs on a college campus. In response to this, Grigal et. al (2011) have created clear guidelines and standards that promote best inclusive practices. Yet, as Hughson and Uditsky (2019: 58) argue-the taxonomy created in the US does not seem concerned with value-oriented perspectives and practices, instead these attempts to standardize programs assume that this is necessary to create "comparative research on program efficiency and population outcomes for this group of people."

Thus, based on the broad research body, it seems that goals and desired outcomes of postsecondary programs for students labeled IDD are most often framed in four domains: academic, social, independent living, and vocational. Each of the domains and outcomes are typically addressed or measured in terms of skill-development or impressions of competence in relation to 
student participation in a college program (c.f., McEathron et al., 2013; Thoma, et. al, 2011). Common topics in literature conform to the four domains and describe program aims, outcomes, and student characteristics, strengths, and needs using concepts such as self-determination, self-advocacy, academic support, socialization, life skills, and social skills, and often emphasize the role of IPSE to prepare students for employment and independent living (c.f., Berg et al., 2017; Hendrickson et al., 2013; Rilotta et al., 2018; Rogan et al., 2014). Many of the skill-oriented priorities align strongly to goals and outcomes associated with K-12 special education priorities and outcomes, and seem more prescriptive than traditional goals set by institutions of higher education. O'Brien (2019) advocates that students should be able to develop their voices and pursue their interests through immersion in authentic student experiences, in which case "curricular focus on life skills or self-advocacy is an unnecessary distraction" (O'Brien, 2019: 272) to authentic learning.

An additional concern is that as studies on IPSE programs are increasing in volume in recent years, student voices, unfortunately, continue to be left out of much of the research (Vroman, 2019). We further Vroman's critique of the body of literature through our own analysis, finding that student perspectives are less often collected and/or less often reported in IPSE research as compared to the perspectives of other stakeholders. From the extant literature on IPSE, we found twelve articles that include direct quotes from IPSE program participants with disabilities.

Of these articles, some studies illustrate differences between how students and other stakeholders describe their experiences of IPSE, which are important for program development. Neubert and Redd (2008), for example, point out differences between student participants' impressions and goals and those of other research participants, which included family members and IPSE staff. They describe students as seeing themselves living on their own and getting married, while their family members envisioned group homes or supervised apartments with little awareness of resources for supported living and did not describe marriage as a future expectation. Berg et al. (2017) report, "A greater percentage of nonstudents (91\%) compared with students $(6 \circ \%)$ indicated that social skills (e.g., interpersonal skills, social responsibility) were a challenge" (p. 5). They further state, "Although $100 \%$ of nonstudents shared that self-advocacy, initiative and motivation to succeed in college, empathy, respect, and self-awareness were critical for PSE goal attainment, only $30 \%$ of students mentioned these characteristics" (p. 6). During a qualitative study involving discussion groups of IPSE students Mock and Love (2012: 295) emphasized students "difficulties with successfully advocating for more opportunities such as, meeting new people, 
taking more classes, and attending the college of their choice." The student group further expressed desire to receive "more information earlier to better self-advocate for a college option;" having "diverse options on campuses with access to courses; and "having "better preparation in high school to take college classes" (Mock and Love, 2012: 292). Students also described the desire to be the primary contact for college communication, rather than a parent or family member, and one student in the study noted the need for support in understanding their own needs and entitlements related to disability early in education.

While the cases are not posed for direct comparison given the differences in participants and research contexts, the idea that different methodologies and the vocabularies used in research may influence how participants are able to describe their impressions is worth consideration (Nind and Vinha, 2014; Vroman, 2019). Talking about options, choice, wanting more information, and earlier access to learning about disability and college, as participants in Mock and Love (2012) did, seem to characterize ideas of advocacy, self-advocacy, and initiation. However, this language was not necessarily used or selected by students, with respect to Berg et al.'s study (2017). It seems important to consider the impact that methodology and interpretation have in understanding data emerging from studies on IPSE. Differences in stakeholder impressions may be rooted in significantly varied aims, knowledges, and hopes for what it means to participate in college programming, while other differences in how the experiences are described may be produced by methodologies used to collect information. In other words, it is not clear whether researchers and student stakeholders are using the same vocabulary or whether the vocabulary used means the same thing to all parties. These kinds of differences highlight the importance of considering "the desired outcomes of post-secondary and higher education and, as Corby et. al (2018:15) question: "Who should be defining these outcomes"?

The present study extends the body of work that emphasizes disabled student perspectives in research and attends to words and contextual meanings that students use to narrate their experiences about participating in campus activities. Because DSE research aims to attend closely to participants' understandings and perceptions, we recognize that disability is an experience and identity that is contributive and that shapes one's worldview. Thus, our commitment to DSE informs our presumption that disabled research informants express and act with desire and agency, and that they are trustworthy narrators of their perspectives and experiences (Taylor, 2018). We contend, then, that participants' voices and descriptions of IPSE should be a primary source in conceptualizing IPSE aims and outcomes. 
The ICP project is located at a comprehensive public university in the Northeast, USA with approximately 20,000 undergraduate and graduate students. The racial composition of the students at the University is $47 \%$ White, 29\% Hispanic/Latino, 13\% Black/African-American, 6\% Asian, and 5\% who identify in other groups. Approximately $10 \%$ of the students at the university are registered with the Office of Disability Services. All participants in the ICP project were labeled as disabled while in K-12 school and all currently qualify for disability-related support and services either through their school district or through adult service systems.

At present, ICP programming is best described as a transition-to-college experience, in which the intent is to provide participants with perspective on what college is like. The ICP is driven by peer fellowship where undergraduate students provide companionship and academic support to create an apprenticeship context for learning about college life. Participants, called "fellows" in our everyday parlance engage in a range of peer-supported activities while on campus. Many ICP students choose to audit 1-2 courses per semester that they select in departments and colleges across the University. A few examples of courses that have been audited include: New Student Seminar, Music In Film, Topics in Global Art Cultures, Beginning American Sign Language, and Perspectives on Early Childhood and Elementary Education. Students attend audited courses with peers, and also complete work and assignments with peer support. When not engaging in academic activities, students are able to participate in all that the campus has to offer. Some sample activities that students engage in include working out and playing games at the recreation center, attending campus wide social events, eating and hanging out in dining halls, and visiting dorms or other "hang out" spaces on campus with peers.

\subsection{Research Informants}

The two-year study conducted between 2016-2018 includes $5^{\circ}$ consenting informants, including ICP program participants, family members, school and partner staff, peers, professors, and other stakeholders from the campus and community. Thirty-one research informants are ICP participants who are labeled with IDD. The research team consisted of two co-principal investigators (the co-authors) and involved five student research assistants. Student research assistants included 2 undergraduate students that were paid as part of an internal grant, 2 graduate assistants who received tuition reimbursement to work with the ICP, and 1 undergraduate student volunteer. Throughout the data collection process, the research team met regularly. Initially meetings 
were dedicated to training on qualitative data collection and participant observation methodologies in education (Bogdan \& Biklen, 2007). As data collection progressed, meetings focused on sharing and discussing data and reflecting on the research process.

All ICP participants were invited to take part in a qualitative research study one month after they began the program. Of the total who were invited to participate in the study, $74 \%$ agreed to participate through the Institutional Review Board-approved process of informed consent or assent. Student research assistants were a regular part of ICP activities, including going to classes as peer companions/supporters. The self-reported demographic characteristics of the ICP fellows who participated in the research are: $42 \%$ female, $58 \%$ male; $68 \%$ White, $10 \%$ Hispanic, $13 \%$ Black or African-American, $3 \%$ Asian, and $6 \%$ who declined to self-identify their race. In the write up of this research, all research participants have been assigned pseudonyms in order to protect their privacy.

\subsection{Data Collection}

Data were collected through participant observation and artifact gathering. The research team recorded video and audio, took photos, and wrote field notes while engaged as participants in regular ICP activities and during group debriefing sessions. The vast majority of data in this report were collected by student research assistants. Student research assistants also participated in ICP experiences on days when they were not collecting data, which enabled their positionalities to blur across the peer-participant and researcher roles. Artifacts were gathered by taking photos in situ and accessing assignment submissions and instructor feedback using the university's online course management system. Artifacts include course assignments and products created by participants as part of ICP-specific program activities. Products include posters, portfolios, and digital presentations created by participants and peers for display at the end of each semester. Video, audio and photographic data collected on 55 days distributed throughout Fall 2016-Spring 2018 (about one day per week, with multiple researchers collecting on same days).

\subsection{Data Analysis}

A qualitative data analysis process generally derived from grounded theory and described by Saldaña (2015) as a multiple phase process characterized by coding, categorizing, and confirming, was used. Principal investigators separately coded all data. The first round of coding was an iterative process of establishing descriptive codes. The investigators compared codes and text samples to arrive at agreement and generate a working vocabulary for the data set. We then organized codes into categories by proposing relationships among 
the data. In a third pass we proposed themes using constant comparison to test propositions against a holistic understanding of the data set, informed by our experiences and reflections of being participant observers and members of the everyday life of the ICP project.

We use an interpretivist approach to research, which acknowledges that understandings brought forth in research are partial and shaped by gendered, raced, abled, and classed discourses that shape human relationships in the broad cultural context of the study. Neither researcher identifies as disabled; Both have spent their careers as teachers, teacher-educators, and scholars who advocate for disability rights and inclusive schools and societies. As trained qualitative and interpretivist researchers, we embrace the insider's insight that we bring to analysis, which provides a stronger and more precise sense of context necessary to understanding the phenomena we view on video and in informants' work products. The majority of field data was collected by student research assistants and the primary sources of data across the study are video recordings, audio recordings, and artifacts, which are able to be viewed and analyzed over time, multiple times, and by various interpreters.

\section{$5 \quad$ Findings}

Two themes that emerged as centrally important for ICP participants are 1) relationships and 2) in(ter)dependence. These themes arose throughout various types of data including student work, audio and video clips of discussions, interviews, focus groups, debriefing sessions, and participant-observation. We choose to report on these because participants' narration and description of these concepts seem important to consider in terms of the broader literature base that defines and prioritizes academic, social, independent living and vocational development as the primary domains of interest that IPSE programming should center.

\section{1 "When I Was With the Fellows": Relationships, Support, and Reciprocity}

Desiring to meet people and spend time with other college students was a frequent topic for nearly all informants and descriptions of people from the perspectives of program participants were the most robust categories that emerged through our analysis. Questions that guided establishing categories during analysis were: Who are the people informants mention? How do they characterize these relationships? What ways do participants describe or provide evidence of "belonging" to the University community? We provide several 
examples of different types of relationships described by program participants that elucidate various ways informants described people and relationships.

Liam described several people during a writing activity he completed for a course that he was auditing:

Last Monday I went ice skating [at the University]...To prevent me from falling I went ice skating with a walker that [the ice rink] provided, the boring part was that I had to stay in a corner away from the rest of the skaters with [sic] was upsetting in some ways because I was looking forward to meeting new people and making acquaintances with new faces...Overall when I was with the fellows at [the ice rink] I learned some new skills like being open to try new things like ice skating and I developed good self-esteem because I got to converse with the rest of the group and with the fellows in the rink and on the outside of the rink, it was a nice experience/trip.

Liam refers to people in four different ways. "Rest of the group" refers to other students from his high school. "The fellows" refers to university students who are in planned partnerships with ICP participants; and "new people" and "new faces," refers to unknown university students. Liam's writing expresses relationships and positionality within those relations. Liam positions himself as part of "the group." Planned partners ("fellows") are specifically named, therefore positioned differently from people he may meet in unplanned encounters. Liam continues his discussion describing his desire to meet others outside of these groups, and he later states: "I'm happy to be a fellow here at [the University]."

Others participants described people differently. Lena wrote, "My favorite subjects are math and science! When visiting [The University] I sat in on a math class with one of my fellows!" She expresses a specific and personal relationship with peers, denoting one as "my" fellows. This is in contrast to Roger who described in talk, "Like the fellow showed us things at campus." Roger's reference to "the" fellow is more distant than the relationship Lena connotes. During a conversation with a student researcher, when George was asked whether he talks with other students in his class, he replies he does and describes: "we talk about what's going on... how they're doing in other classes and all... We talk about more than just class. We talk about what careers they're gonna have in the future... how they're gonna live after they graduate." George also notes that in response to what he shares, other students tell him, "that's fantastic... [and] I hope I see you again one day."

Others named relationships and friendships that have evolved through participation in the ICP. In PowerPoint presentations fellows created to reflect 
highlights of the semester, relationships and friendships came up frequently. For instance, Gerard created a slide with text and a "selfie" photo of he and Tom, a peer. Gerard writes: "[Tom] is awesome person. We have been hanging out at [the University]. [Tom] is a good friend of mine. We talk about pranks a lot. I like to eat lunch with [Tom]". Abigail noted that a highlight of her time was "playing racquetball and ping pong with friends," while Marcus explained that he "loved to be here because he loved to spend time with his friends," which was set next to a photo of a group of fellows. Nicole discussed her relationship with her mom and her family throughout her presentation, and also stated that: "the students are really nice here and [Delilah] is my college friend." Chloe also discussed friendship, but in a way that seems more aspirational rather than accomplished through her participation in ICP. She stated: "I am very friendly and outgoing. The people at [the University] are also friendly and very smart... I like coming to [the University]..." Chloe's description of "the people" at the University is a bit more distant. Perhaps she wants to get to know "the people," but has yet to accomplish this goal. We also wonder how Chloe is comparing and contrasting her sense of self as "outgoing" with her impression of others as "very smart," in terms of experiencing cross-disability relationships.

Additionally, our data revealed participants in the pre-employment program talking or writing about family members, siblings, and relationships they have with other people with disabilities from the programs they attend during the day. However, there was rarely mention of non-familial friends or friends outside of their programs. The interest of ICP participants in meeting people and the frequency with which they highlight forming relationships and companionship-even if ICP is context-bound - should not be understated. It could be that for many participants being in the ICP is a primary way that they have been able to socially interact and form bonds with people outside of their families, or who are not participants in the programs they attend. The frequency with which this is mentioned leads us to interpret its importance to participants.

ICP participants also saw their own participation in reciprocal relationships that were built on campus, highlighting their sense of belonging. One example is from Collin who described his experience during his first semester in the ICP during a debriefing session. A staff member described that she felt it was beneficial that ICP participants learned from another group of university students and Collin asserted that "they got to learn from us, too." His staff agreed, and Collin continued: "Feeding off of each other-you feed off us and we feed off you too." Collin continued to talk about how he learned various other lessons from his time on campus such as the importance of attending college before you get a job, and how long college students are on 
campus ["from 8am until midnight if you have to"] compared to the 6 hours he attends in his pre-employment day program. Then, a peer asked him if he learned anything else, and Collin claimed: "I learned that it's not just all about you, it's all about how you share. Because you can't just, like, go run a sports team and say "Okay, this is a one-man crew... It's a team effort." Throughout Collin's narrative, he asserts that he contributed as strongly as the fellows that he encountered, who his staff asserted he had learned from. This highlights the importance of reciprocity in learning and that belonging is about everyone contributing in particular ways to relationships. Beyond the contributions he felt he made to the learning of the group, he additionally described that he believed a key to being successful in college is about working collaboratively.

Carl described his relationship with Megan, a peer who supported him in auditing a course. During a group discussion, Carl, who audited a journalism course, described the course as "pretty hard." He says: "From the beginning, we didn't have [Megan] ...it was like aggravating to me and to Ms. J. too, but since we have somebody to help us out... It's going pretty good now." Megan was a university student and student researcher assigned to work with Carl mid-way through the class. Ms. J is the paid staff assigned by his high school to support Carl on campus. Once Megan stepped into the role to provide peer support, Carl found the workload and course expectations manageable.

It seems important to consider the various ways ICP participants are thinking about people, relationships, and friendships on campus. Doing things "with friends" is connected, for Liam, with trying new things and developing good self-esteem, and, for Abigail, with playing games. For Carl, working with Megan changed his course experience from being "aggravating" to "going pretty good." We learn from participants that opportunities to form relationships and engage in activity with others is a key component of the ICP. This echoes other research that highlights social opportunity and engagement as main goals and benefits of IPSE (Corby et al., 2018; Prohn, et al., 2016; Spassani et al., 2017; Vroman, 2019). Socializing at college (Spassani et al., 2017), bonding with other students (Prohn, et al., 2016), and focus on friendships and relationships with family and staff (Corby et al., 2018) are frequent benefits and hopes stated by IPSE participants.

Important to think about is the variety of type of relationship described by ICP participants. Planned companionship, opportunities for chance encounters, and how these differ from planned support relationships, subtly, but importantly suggest that companionship as part of social experience is noted more often than peer support for developing "social skills" by IPSE students. In Carl's case, having a peer in an academically supportive relationship enabled success. Notable here is the difference between having a 
supporter skilled in the course topic as differing from having general support, as initially provided by Ms. J. Further research can consider how planned peer relationships figure into participants' broader constellation of relationships, which may expand understanding about the purposes and aims of the common use peer-supported programming in IPSE (Eisenman et al., 2013; Thoma et al., 2011).

\section{2 "I Want to Someday Live On My Own, Like with a Friend:" On Interdependence}

Striving toward independence is a common goal noted in IPSE literature. Students report desiring "freedom" from support staff and having choices in academic and social experiences (Neubert and Redd, 2008). Other students describe the importance of participating in IPSE to having a new identity and being able to reinvent oneself (Paiewonsky, 2011), as well as the feeling of viewing oneself differently in terms of capability in learning and literacy (Folk et al., 2012). For ICP participants, "independence" was referred to directly, but seemed to reflect a concept closer to interdependence. In an end of semester debriefing meeting, Millie stated that she enjoyed "being here with these beautiful people and looking at the dorms and the college rooms, and the gym." Then Kira, her staff member from the pre-employment center asked, "But what did you learn from it?" Millie responded: "I learned that being independent is really a lot of fun." Kira then turned to Millie, and stated: "You guys know how to be independent. Some of you like to lean on others, for it. But in the process you guys have learned it, because [staff] were here we did not help you do your math project, you guys did it all on your own." Millie then replied "I like doing my math homework with [Steve]." Although Millie brought up independence as something she felt was "fun," she contrasted Kira's comment on independence. When pressed to see herself as "independent" by her staff, she resisted that idea and stated her enjoyment of doing homework with Steve, instead highlighting interdependence as a source of pleasure.

Several fellows also brought up independence and interdependence in relation to goals of living on their own. During an activity where the fellows were working together to discuss future goals, Keenan noted that he wants "to be as independent as possible because I want to someday live on my own, like with a friend." Similarly, Lee expressed his desire to change his living situation. He stated: "My favorite thing that I like about [the University]... how am I going to move out of my own house and move on? Like maybe I can come here so I can live here so I can have all of the new students be my new family and my new friends... I want my college degree and I want to come here." Both Keenan and Lee assert that they have goals to live more independently, but neither 
express a desire to live alone; Keenan states he wants to live with a friend, and Lee states that he wants to live on campus and have new students be his new family and friends. Both narratives further develop the theme that although they may be striving for "independence", they see living with others as part of this experience. Thus independence, for these participants, is not equated with doing things alone or living alone. Rather, it is associated with doing or living with "Steve," a "friend," or "all of the new students," respectively.

Alexis also describes her desire to live "independently, but not alone." When asked about what she had learned by being on campus that semester, she stated: "I learned to be independent." The staff responded "how so?" and Alexis said: "I want to get my own apartment." During a different conversation, Alexis also said: "I would be happy to be here, to be a student here, and learn something new." A peer asks: "would you want to live on campus?" and Alexis says: "I want to- I love that stuff- away from my family, it's chaos." Later in this same conversation, Alexis asserts: "I have dreams-I wanna get married to my boyfriend-He can call me 'my wife'! I wanna live with him."

In each of these discussions that occurred as part of everyday talk, we see that ICP participants have goals, some of which directly were connected to goals of going to college-like for Lee-and others, related to (inter)/independent living. Notably, all of the fellows who described seeking a change in their living situation attend the pre-employment center in which setting personal goals, such as becoming more independent, is a program aim. Although we think that it is possible they have adopted some of the discourses about working on "independence" from the conversations happening at the agency they attend, it is important to highlight that when fellows described their interest in becoming independent, they also included other people as being part of their journey. Independence means breaking away from family and highlighting other students, friends, or a potential spouse as being a companion. Independence, then, is not equated with doing things on one's own, as much as doing things with peers or in relationships of choice.

\section{Discussion}

Key themes from studies that emphasize IPSE student perspectives yield several understandings that can inform IPSE program development through a DSE perspective, and that can simultaneously inform DSE scholars about the burgeoning field of IPSE. Abundantly clear is the emphasis on college education as an experience defined by personal achievement, being socially active, and the opportunity to learn by taking classes of interest, which highlight facets 
that extend or perhaps even differ from more commonly stated aims of IPSE as being primarily for employment and skill development toward independent living (Corby et al., 2018; Papay and Bambara, 2011).

In contrast, research studies that center student voice show that IPSE participants highlight the importance of having safe spaces in which others are accepting and supportive (Kubiak, 2017), have the need for being treated with respect by IPSE staff and university faculty (Mock and Love, 2012), and that they feel a part of a community when given the opportunity to learn about disability culture and identity (Spasianni et al., 2017). Friendship development has been found to be a positive outcome of IPSE programs. Corby et al. (2018) interviewed students about their experience going to college, and found that making friends was one of the most important aspects of attending college. In particular, they found that participants referred to planned peer mentors as "friends" more often than other peers they came into contact with around campus. O'Brien et. al (2009) additionally found that students expressed the benefits of making friends during college outside of the friendships they developed within disability-segregated agencies. Vroman's (2019) results showed that students frequently described various types of friendships they developed in the college program. Similar to these findings, ICP students talked about the friendships they made on campus differently than the others they also discussed as important to their lives; for instance, the other students who attend the disability-specific programs with them in the pre-employment center or transition program or family members. These experiences may be unique because many participants who have come to ICP through partner pre-employment and transition programs have not been provided many opportunities to develop relationships with peers in disability-integrated educational experiences.

As we continuously struggle with and evaluate the best ways to approach planned peer relationships as may be different from "naturally" formed connections as we develop the ICP, it is important to understand that participants clearly identify developing relationships and having the opportunity to interact with college-aged students as an important part of their experience. We have also noticed that peer support is important to the success of fellows in classes, which was particularly evident when Carl described the importance of Megan's assistance in his class. Additionally, participants described planned fellow relationships as important, while Liam and George noted the importance of opportunities to engage in unplanned interactions with other students in classes or across campus.

A DSE critique of the ICP or other post-secondary college opportunities that schedule peer support might be that when students spend time together because of a course requirement, a service commitment, or for pay, relationships 
might have problematic power-dynamics or they may not be authentic. Van Der Klift and Kunc (1994), for example, critique "the politics of help" that are often structured in classrooms between students with disability labels and those without in K-12 classrooms. The authors critique that power-dynamics are often set up in such relationships, where it reaffirms that students with disabilities must always accept help, and those without must give help, which they felt hindered true and reciprocal friendship building. When we structure peer supports we are setting up a dynamic that may correspond to giving and receiving help. It is essential, then, to emphasize reciprocity in our approach to thinking about planned peer relationships. In a classic text, Bogdan and Taylor (1989) describe a framework that they call a "sociology of acceptance" that describes how people with significant disabilities, who are often considered "deviant" by society, come to be accepted as friends to people in their lives. Bogdan and Taylor noted that many of the friendships they observed began as a staff-client relationships, but through getting to know each other they built reciprocal friendships that existed outside of the formal structures of client/worker roles. struggle with

Lutfiyya (1991) also studied how friendships formed between people with significant disabilities and those without. She, too, found that although many friendships started through a formal arrangement in a staff/client structure, feelings of reciprocity, mutuality, and enjoyment were what allowed for the development of what were qualified as "friendships." Lutfiyya also found that relationships that started as transactional, grew to being framed as friendships when both parties in the friendship considered that enhanced level of relationship to be voluntary, mutually chosen, and accepted. Our ICP relationships are facilitated by the structures of the university program, but most are not paid positions. One reason we call both traditionally enrolled college peers and those who are part of the ICP "fellows" is an attempt to mitigate a static power dynamic of giver and receiver of help.

While we continue to reflect on facilitating planned relationships, it is important to consider that at least one research participant, Collin, described feeding off of each other in a reciprocal way as an impression of the ICP. This is one example that contrasts Nasr et al.'s (201:12) finding of an IPSE in which, "The support that is given and taken from the participants with people from out of [the IPSE] program is mostly unequal," which they describe as a barrier to forming long-term friendships. That stated, also important is to unpack the normative assumptions that may underlie notions of friendship. Is there only one way, for example, to experience friendship, and to what extent might this idea reflect compulsory ablemindedness or inclusionism? In what ways do peer relationships formed in IPSE s emerge as mutually satisfying and enriching? We acknowledge and attend to concerns about power and reciprocity as 
we consider how to set up peer supports, while also being mindful that all relationships develop in unique ways and there is value for participants to have the opportunity to engage alongside college-aged peers, which may or may not lead to a normative construct of friendship. Also important is consideration of how to best educate peers through a DSE perspective (e.g., teaching them about disability justice, the social model of disability, critical disability studies, etc.), so that they can question disabling conditions that ICP fellows encounter, resist and critique dominant and deficit-oriented discourses, and develop reciprocal and interdependent relationships through fellowship.

\subsection{In(ter)dependence}

In IPSE and other literature (e.g. Berg et al., 2017; Hendrickson, et. al, 2013) independence is often emphasized as a goal. While independence in life and learning may be a desired aim, caution is warranted in ensuring that a drive toward independence does not devalue individuals with significant, ongoing support needs or the accomplishment that may be gained through support and supportive relationships. A danger is that students with disabilities are only provided access and opportunity on that which seems achievable "independently," which can shut them out of experiences that may be more interesting, desirable, or beneficial when engaged in with support. Historically, many people with IDD labels have been casted as either completely dependent on others or a system of supports, or they are told that they must strive to regain independence in order to reach full personhood. Ds scholars critique the idea that becoming "independent" is attainable or desirable for most people. Wendell (2006), for example, describes:

There are disabled people who will always need a lot of help from other individuals just to survive (those who have very little control of movement, for example), and to the extent that everyone considers independence necessary to respect and self-esteem, those people will be condemned to be devalued. In addition, some disabled people spend tremendous energy being independent in ways that might be considered trivial in a culture less insistent on self-reliance; if our culture valued interdependence more highly, they could use that energy for more satisfying activities. (p. 252)

Wendell continues in recommending to build a framework of interdependence, rather than holding "independence" as a gold standard of success.

Noted earlier, it is problematic to compare how well people with IDD labels measure up to ideals that it is assumed non-disabled people have mastered. 
Most people rely on social networks and supports; all people live interdependent lives, which are productive and valued concepts for IPSE s to consider. Many ICP participants articulate their desire to increase "independence" in their lives, and many see participating in college as a way to reach those goals. However, it is also clear that "independence" is equivalent to reciprocal and interdependent relationships. This allows us to think about emphasizing mutuality in relationships so that the fellows who are enrolled in a traditional college program develop an understanding of interdependence and give and take. Using the college experience to support fellows and their staff to develop language outside the dependent/independent binary may help all people understand the importance of proper support that we all need when working towards individual goals. We continue to find this framework instructive as we structure supports and work with ICP fellows to determine personal goals.

\section{Conclusion}

Postsecondary programs that emphasize college learning, are designed for students with IDD labels, and integrate disabled and non-disabled students for at least $50 \%$ of the time can apply to the United States Department of Education to be labeled as a Comprehensive Transition Program. Think College is currently developing an accreditation system to evaluate the structure and quality of IPSE programs using eight standards (National Coordinating Center Accreditation Workgroup, 2016). Grigal and Hart (2011) discuss eight standards and the range of approaches to them that are apparent in IPSE. The standards address: academic access, career development, campus membership, self-determination, alignment with college systems and practices, coordination and collaboration, sustainability, and ongoing evaluation. It is clear that organization of purposes, aims, and structures for IPSE are moving toward coherence.

We found differences and tensions between what college students say they gained and what their staff and the literature claim the outcomes "should" be from IPSE experiences. Consider that Papay and Bambara (2011) surveyed 52 program coordinators of PSE-IDs in 2008 and analyzed that participating in college classes was less frequently emphasized by survey respondents. They write: "This finding suggests that we could perhaps refer more accurately to programs based on college campuses as employment programs based in age-appropriate settings rather than as postsecondary education programs." (p. 9o, emphasis in original). Similarly, O'Brien (2019) similarly critiqued such attempts towards standardization buy instead urging IPSE to focus on creating 
opportunities for students to engage in authentic student experiences, with necessary supports in place.

Similar to O'Brien (2019), we argue for an embracive view of all that college has to offer. It is certainly the case that in broader higher education discussions there may be differences between what parents, faculty, and staff hope traditionally enrolled college students take from college and what students would report they gain and desire from their time in college. Thus, we recommend caution in tying the ongoing development of IPSE s to a narrow vision of what college experiences can offer. Students' perspectives are not merely secondary, incidental, or soft gains of college, but should be attended to in full. In other words, IPSE s-like college, generally-is not only about employment or academic learning. Students take away much more. As Folk et al. (2012: 26o) note, for example, "the reasons for [student] growth likely extend beyond the quality of college instruction and content and have more to do with the expectations and values incumbent in [IPSE] settings." IPSE can strive to adopt values that emphasize interdependence and intentional expansions of relationships and social opportunities, as guided by those experiences that IPSE participants are reporting as most meaningful.

Perspectives and research methodologies that reflect the commitments and critical lens of DSE broaden the kind of data that is collected and reported to further develop IPSE programs as they strive to be inclusive. There is opportunity posed in resisting and interrupting professional discourse as the primary context in which IPSE $s$ are considered and the chief way that outcomes of such programs are measured. We can examine how disabled students narrate their own experiences and resist categorizing these tellings in relation to how well they are performing "social skills" or "socialization," different from forming relationships and pursuing social opportunities; or how well they are being independent, different from living and learning interdependently. It is critical that perspectives of IPSE participants are gathered and interpreted with careful attention to informants' meanings to ensure student voice is central in program development.

\section{References}

Berg, L. A., Jirikowic, T., Haerling, K., and MacDonald, G. (2017). Navigating the hidden curriculum of higher education for postsecondary students with intellectual disabilities. The American Journal of Occupational Therapy, 71(3): 1-9. 10.5014/ ajot.2017.024703.

Bogdan, B. and Biklen, S. (2007). Qualitative research for education: An introduction to theories and methods (5th Ed.). Pearson. 
Bogdan, B. and Taylor, S. (1989). Relationships with severely disabled people: The social construction of humanness. Social Problems, 36(2), 135-148. 10.2307/800804.

Campbell, F. K. (2009). Contours of ableism: The production of disability and abledness. New York, NY: Palgrave Macmillan. 10.1057/9780230245181.

Corby, D., Taggart, L. and Cousins, W. (2018). The lived experiences of people with intellectual disabilities in post-secondary or higher education. Journal of Intellectual Disabilities. https://doi.org/10.1177/17446295188056o3.

Danforth, S. and Gabel, S. (2006). Introduction. In S. Danforth and S.L. Gabel (Eds.), Vital questions facing disability studies in education (pp.1-15). New York, NY: Peter Lang.

Eisenman, L. T., Farley-Ripple, E., Culnane, M. and Freedman, B. (2013). Rethinking social network assessment for students with intellectual disabilities in postsecondary education. Journal of Post-secondary Education and Disability, 26(4):367384. http://fac.ksu.edu.sa/sites/default/files/jped26_4_full_document.pdf\#page=89.

Federal Student Aid. (2018). Students with intellectual disabilities may be able to get certain types of federal student aid. Retrieved from: https://studentaid.ed.gov/sa/ eligibility/intellectual-disabilities.

Folk, E. D. R., Yamamoto, K. K., and Stodden, R. A. (2012). Implementing inclusion and collaborative teaming in a model program of postsecondary education for young adults with intellectual disabilities. Journal of Policy and Practice in Intellectual Disabilities, 9(4), 257-269. https://doi.org/10.1111/jppi.12007.

Grigal, M., Hart, D., and Weir, C., (2011). Think College Standards Quality Indicators, and Benchmarks for Inclusive Higher Education. Boston, MA: University of Massachusetts Boston, Institute for Community Inclusion. https://www.mass.edu/ strategic/maicei/documents/think-college-standards.pdf.

Grigal, M., Hart, D., and Weir, C. (2012). A survey of postsecondary education programs for students with intellectual disabilities in the United States. Journal of Policy and Practice in Intellectual Disabilities, 9(4), 223-233. https://doi.org/10.1111/jppi.12012.

Hendrickson, J. O. M., Vander Busard, A. M. Y., Rodgers, D., and Scheidecker, B. (2013). College students with intellectual disabilities: How are they faring? Journal of College and University Student Housing, 39/40(2/1), 186-199. https://eric. ed.gov/?id=EJ1161633.

Hughson, Anne and Uditsky, Bruce (2019). 30 years of inclusive postsecondary education: Scope, challenges and outcomes. In Patricia O'Brien, Michelle Bonati, Friederike Gadow and Roger Slee (eds.), People with Intellectual Disability Experiencing University Life: Theoretical Underpinnings, Evidence and Lived Experiences, pp. 267-276. Netherlands: Brill.

Kafer, A. (2013). Feminist, queer, crip. Bloomington: Indiana University Press.

Kristiansen, K., Vehmas, S., and Shakespeare, T. (Eds.). (2008). Arguing about disability: Philosophical perspectives. Routledge. 
Kubiak, J. (2017). Using "voice" to understand what college students with intellectual disabilities say about the teaching and learning process. Journal of Research in Educational Needs, 17(1): 41-48. https://doi.org/10.1080/o3323315.2015.1025532.

Linton, S. (1998). Claiming disability. New York, NY: New York University Press.

Lutfiyya, Z. M. (1991). 'A Feeling of Being Connected': Friendships between people with and without learning disabilities. Disability, Handicap and Society, 6: 233-245. https://doi.org/10.108o/o2674649166780271.

McEathron, M. A., Beuhring, T., Maynard, A., and Mavis, A. (2013). Understanding the diversity: A taxonomy for postsecondary education programs and services for students with intellectual and developmental disabilities. Journal of Postsecondary Education and Disability, 26(4), 303-320. https://eric.ed.gov/?id=EJ1026907.

McRuer, R. (2006). Crip theory: Cultural signs of queerness and disability (Vol. 9). New York: NYU press.

Mitchell, D., Snyder, S., and Ware, L. (2014). "[Every] Child Left Behind" Curricular cripistemologies and the crip/queer art of failure. Journal of Literary and Cultural Disability Studies, 8(3), 295-314. 10.3828/jlcds.2014.24.

Mock, M., and Love, K. (2012). One state's initiative to increase access to higher education for people with intellectual disabilities. Journal of Policy and Practice in Intellectual Disabilities, 9(4): 289-297. https://doi.org/10.1111/jppi.120o6.

National Coordinating Center Accreditation Workgroup. (2016). Report on Model Accreditation Standards for Higher Education Programs for Students with Intellectual Disability: A Path to Education, Employment, and Community Living. Boston, MA: ThinkCollege National Coordinating Center. https://sites.ed.gov/naciqi/ files/2017/o2/acc-accrediation-report_FINAL.pdf.

Neubert, D. A., Moon, M. S., Grigal, M, and Redd, V. (2001). Post-secondary educational practices for individuals with mental retardation and other significant disabilities: a review of the literature. Journal of Vocational Rehabilitation, 16(3/4):155-168. https:// content.iospress.com/articles/journal-of-vocational-rehabilitation/jvroo124.

Neubert, D. A., and Redd, V. A. (2008). Transition services for students with intellectual disabilities: A case study of a public school program on a community college campus. Exceptionality, 16(4), 220-234. https://www.semanticscholar.org/paper/ Post-secondary-educational-practicesforwithandANeubertMoon/18da7b6oa5fec83 b3e40864f6b72d6d5e $71276 \mathrm{c} 6$.

Nind, M., and Vinha, H. (2014). Doing research inclusively: Bridges to multiple possibilities in inclusive research. British Journal of Learning Disabilities, 42(2), 102-109. https://doi.org/10.1111/bld.12013.

Nussbaum, M. C. (2006). Frontiers of justice: Disability, nationality, species membership. Harvard University Press.

O'Brien, J. (2019). Exploring the growing edges of inclusion. In Patricia O'Brien, Michelle Bonati, Friederike Gadow and Roger Slee (eds.), People with Intellectual 
Disability Experiencing University Life: Theoretical Underpinnings, Evidence and Lived Experiences, pp. 267-276. Netherlands: Brill.

O'Brien, P. and Bonati, M. (2019). From Institutionalisation to Inclusion. In Patricia O'Brien, Michelle Bonati, Friederike Gadow and Roger Slee (eds.), People with Intellectual Disability Experiencing University Life: Theoretical Underpinnings, Evidence and Lived Experiences, pp. 267-276. Netherlands: Brill.

O’Brien, P., Shevlin, M., O'Keefe, M., Fitzgerald, S., Curtis, S., and Kenny, M. (2009). Opening up a whole new world for students with intellectual disabilities within a third level setting. British Journal of Learning Disabilities, 37(4):285-292. https://doi. org/10.1111/j.1468-3156.2009.00584.x.

Oliver, M., and Barnes, C. (2012). The new politics of disablement. Macmillan International Higher Education.

Papay, G. K., and Bambara, L. M. (2011). Postsecondary education for transition-age students with intellectual and other developmental disabilities: A National Survey. Education and Training in Autism and Developmental Disabilities, 46(1): 78-93 https://www.jstor.org/stable/23880o32.

Paiewonsky, M. (2011). Hitting the reset button on education: Student reports on going to college. Career Development for Exceptional Individuals, 34(1): 31. https://doi. org/10.1177/o885728811399277.

Prohn, S. M., Kelley, K. R., and Westling, D. L. (2016). Studying abroad inclusively: Reflections by college students with and without intellectual disability. Journal of Intellectual Disabilities, 20(4), 341-353. 10.1177/1744629515617050.

Rethinking College [Video file]. (2013). Retrieved from https://thinkcollege.net/ resources/rethinking-college.

Rilotta F., Arthur, J., Hutchinson, C. and Raghavendra, P. (2018). Inclusive university experience in Australia: Perspectives of students with intellectual disability and their mentors. Journal of Intellectual Disabilities. 10.1177/1744629518769421.

Rogan, P., Updike, J., Chesterfield, G., and Savage, S. (2014). The SITE program at IUPUI: A post-secondary program for individuals with intellectual disabilities. Journal of Vocational Rehabilitation, 40(2):109-116. 10.3233/JVR-140673.

Saldaña, J. (2015). The coding manual for qualitative researchers (3rd ed.). Thousand Oaks, CA: Sage.

Slee, R. (2007). 'Its' a fit-up! Inclusive education, higher education, policy and the discordant voice. In , L. Barton and , F. Amrstrong (eds), Policy, Experience and Change: Cross- Cultural Reflections in Inclusive Education. Dordrecht, Springer.

Spassiani, N. A., Ó Murchadha, N., Clince, M., Biddulph, K., Conradie, P., Costello, F., ... Tully, K. (2017). Likes, dislikes, supports and barriers: The experience of students with disabilities in university in Ireland. Disability and Society, 32(6), 892-912. https://doi.org/10.108o/o9687599.2017.1320272. 
Taylor, A. (2018). Knowledge citizens? Intellectual disability and the production of social meanings within educational research. Harvard Educational Review, 88(1): 1-26. https://doi.org/hepgjournals.org/doi/abs/10.17763/1943-5045-88.1.1.

Thoma, C. A., Lakin, K. C., Carlson, D., Domzal, C., Austin, K., and Boyd, K. (2011). Participation in postsecondary education for students with intellectual disabilities: A review of the literature 2001-2010. Journal of Postsecondary Education and Disability, 24(3): 175-191. https://eric.ed.gov/?id=EJ966123.

United States Department of Education (USDOE; 2017). Thirty-ninth annual report to Congress on the implementation of the Individuals with Disabilities Education Act, 2017. https:/www2.ed.gov/about/reports/annual/osep/2017/parts-b-c/39th-arcfor-idea.pdf.

Van der Klift and Kunc (1994). Hell bent on helping: Benevolence, friendship and the politics of help. In , R. Thousand and, A. Villa (Eds.). Creativity and collaborative learning: A practical guide to empowering students and teachers, 21-28. Baltimore, MD: Brookes Publishing Co.

Vroman, K. (2019). "And then you can prove them wrong": The college experiences of students with intellectual and developmental disabilities. (Doctoral Dissertation, Syracuse University, Syracuse, NY). Retrieved from https://surface.syr.edu/etd/1103/. Wendell, S. (2006). "Toward a feminist theory of disability." In The Disability Studies Reader, edited by L.C. Davies, 243-256. New York, NY: Routledge. 